Colloque C2, suppl. au Journal de Physique II, Vol. 1, septembre 1991

\title{
PROPERTIES AND PRACTICAL RESULTS OF TUNGSTEN CARBIDE COATING PRODUCED BY LOW TEMPERATURE CVD PROCESS
}

\author{
S. ICHIJO*, K. TAMURA*, T. TAKANO*, A. NAKAO* and T. HIRAHARA** \\ *Tokyo Advanced Technologies CO., LTD., 5-3-38 Ujina-higashi, \\ Minami-ku, Hiroshima 734, Japan \\ * "Tokyo Hard Coat CO., LTD., 1450-27 Aza-matsubara, \\ Oaza-uenodai, Hukaya, Saitama 366, Japan
}

\begin{abstract}
In forming tungsten carbide layer by low temperature and vacuum CVD, uniformity of film thickness, adhesion and gloss achieved when the effective zone of coating set is increased to $\phi 450 \times 1,100 \mathrm{~mm}$ is described. Characteristics of tungsten carbide layer are evaluated and compared with other materials. Some practical applications to the mechanical parts of plastic injection molding machines are introduced.
\end{abstract}

\section{Introduction}

The technology of forming a tungsten carbide layer, at low temperature by the vacuum CVD, was developed by Archer et al (1:5). The advantages of this tungsten carbide layer forming process are summarized in the following two points.

(1) In the conventional high temperature CVD, the reaction temperature is high, and thermal distortion is caused by heat treatment of the base metal after coating. Vacuum CVD is capable of coating at a temperature lower than the tempering temperature of steel and does not require subsequent heat treatment, thus thermal distortion does not occur.

(2) In both the plasma CVD process and PVD, while it is possible to treat at low temperatures, the throwing power is poor for complicated shapes or for the inner wall of a long hole because the plasma generation region is limited. However in vacuum CVD the throwing power is as good as the conventional high temperature CVD process.

We have been continuing research into this process since 1985 with the purpose of enlarging the reaction volume and making this process practicable. This paper describes the quality achieved when the reaction volume is increased, the results of evaluation of characteristics of tungsten carbide layers, and the results of practical applications.

\section{Increase of Reaction Volume and Quality Achieved}

To use the technique of vacuum

CVD in mass production, it was

necessary to improve the

profitability by increasing the

reaction volume. We attempted to make the quality uniform, with the target of an effective coating zone of $\phi 450 \times 1,100 \mathrm{~mm}$.

The apparatus is schematically shown in Figure 1.

The material gases were $\mathrm{WF}_{\mathrm{B}}$ (99.99\%), $\mathrm{C}_{6} \mathrm{H}_{6}(99.9 \%)$, and $\mathrm{H}_{2}$ $(99.999 \%)$, and $\operatorname{Ar}(99.99 \%)$. Ar gas was used as carrier of $\mathrm{C}_{6} \mathrm{H}_{6}$. In the reactor, in principle, the following reactions take place.
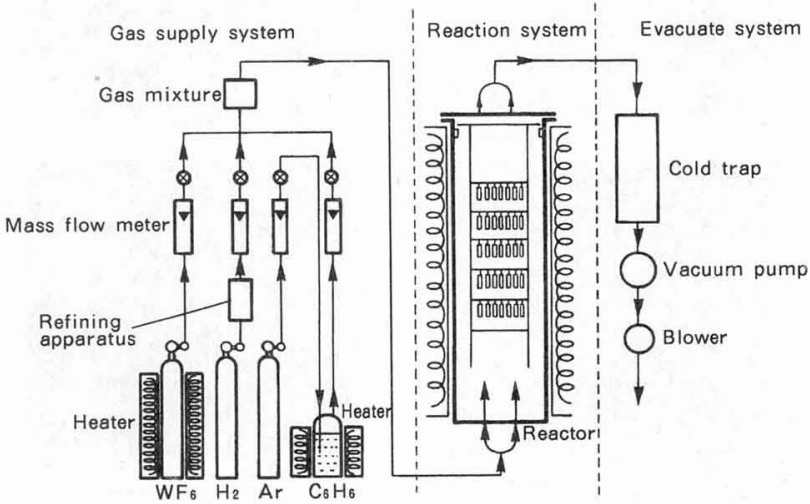

Fig.1 Schematic diagram of tungsten carbide coating apparatus 
$12 \mathrm{WF}_{6}+\mathrm{C}_{6} \mathrm{H}_{6}+33 \mathrm{H}_{2} \rightarrow 6 \mathrm{~W}_{2} \mathrm{C}+72 \mathrm{HF}$ approx. $400^{\circ} \mathrm{C}$ or more

$18 \mathrm{WF}_{6}+\mathrm{C}_{6} \mathrm{H}_{6}+51 \mathrm{H}_{2} \rightarrow 6 \mathrm{~W}_{3} \mathrm{C}+108 \mathrm{HF}$ approx. $300 \sim 500^{\circ} \mathrm{C}$

Depending on the reaction temperature, $\mathrm{W}_{2} \mathrm{C}$ or $\mathrm{W}_{3} \mathrm{C}$ is produced. And the reaction temperature is effected by the pressure in the reactor, the feed gas volume, and the gas mixing ratio. We studied the method of uniformly producing $\mathrm{W}_{3} \mathrm{C}$, which is formed at the lower reaction temperature, for the purpose of preventing thermal distortion.

Table 1 shows the quality evaluation the targets, and the achieved results.

For evaluation of gloss distribution, 150 test pieces of $\phi 30 \times 80 \mathrm{~mm}$ (AISI-1045) were uniformly arranged in a $\phi 450 \times 1,100 \mathrm{~mm}$ zone, together with 9 test pieces of $\phi 50 \times 10 \mathrm{~mm}$ (AISI-M2), for evaluation of distribution of film thickness and adhesion. All test pieces were processed to surface roughness of $R \max 0.4 \mu \mathrm{m}$ or less, and were cọted with $4 \mu \mathrm{m}$ electroless Ni-P plating.

Table 1 Quality evaluation

\begin{tabular}{|c|c|c|c|}
\hline Evaluation items & Method of evaluation & Quality targets & $\begin{array}{l}\text { Present status } \\
\text { of } 10 \text { batches }\end{array}$ \\
\hline $\begin{array}{l}\text { Distribution of } \\
\text { film thickness }\end{array}$ & $\begin{array}{l}\text { Thickness on } 9 \text { test pieces of } \phi 50 \times \\
10 \mathrm{~mm} \text { inserted uniformly in } \phi 450 \times 1100 \\
\mathrm{~mm} \text { zone were measured by ball tester. }\end{array}$ & $8 \pm 2 \mu \mathrm{m}$ & $\begin{array}{ll}\text { Average }(\overline{\mathrm{x}}) & 7.7 \mu \mathrm{m} \\
\text { Scatter }\left(\sigma_{n-1}\right) & 0.7 \mu \mathrm{m} \\
\max & 8.5 \mu \mu \mathrm{m} \\
\min & 6.7 \mu \mathrm{m} \\
\end{array}$ \\
\hline $\begin{array}{l}\text { Distribution of } \\
\text { gloss }\end{array}$ & $\begin{array}{l}\text { Gloss of } 150 \text { test pieces of } \phi 30 \times 80 \mathrm{~mm} \\
\text { inserted uniformly in } \phi 450 \times 1100 \mathrm{~mm} \\
\text { zone were judged visually compared } \\
\text { with } \mathrm{A}-\mathrm{H} \text { gloss standard. } \\
\end{array}$ & $\begin{array}{l}\text { Defect rate of } \\
\mathrm{D}-\mathrm{H} \text { (matte) } \\
3 \% \text { or less }\end{array}$ & $\begin{array}{l}\text { Defect rate of } \\
\text { D } \sim \text { H (matte) } \\
0 \%\end{array}$ \\
\hline $\begin{array}{l}\text { Distribution of } \\
\text { adhesion }\end{array}$ & $\begin{array}{l}\text { Adhesion of the above } 9 \text { test pieces } \\
\text { of } \phi 50 \times 10 \text { were measured by } \\
\text { scratch tester. }\end{array}$ & $35 \mathrm{~N}$ or more & \begin{tabular}{|lr} 
Average $(\overline{\mathrm{x}})$ & $39.8 \mathrm{~N}$ \\
Scatter $\left(\sigma_{n-1}\right)$ & $2.4 \mathrm{~N}$ \\
$\max$ & $43.0 \mathrm{~N}$ \\
$\min$ & $37.5 \mathrm{~N}$ \\
\end{tabular} \\
\hline
\end{tabular}

The gloss corresponded very well to the morphology (grain size) of the tungsten carbide layer film as shown in Figure 2, and therefore, the gloss was evaluated as a measure of morphology. Photo 1, shows the surface structure of the tungsten carbide layer, observed in the

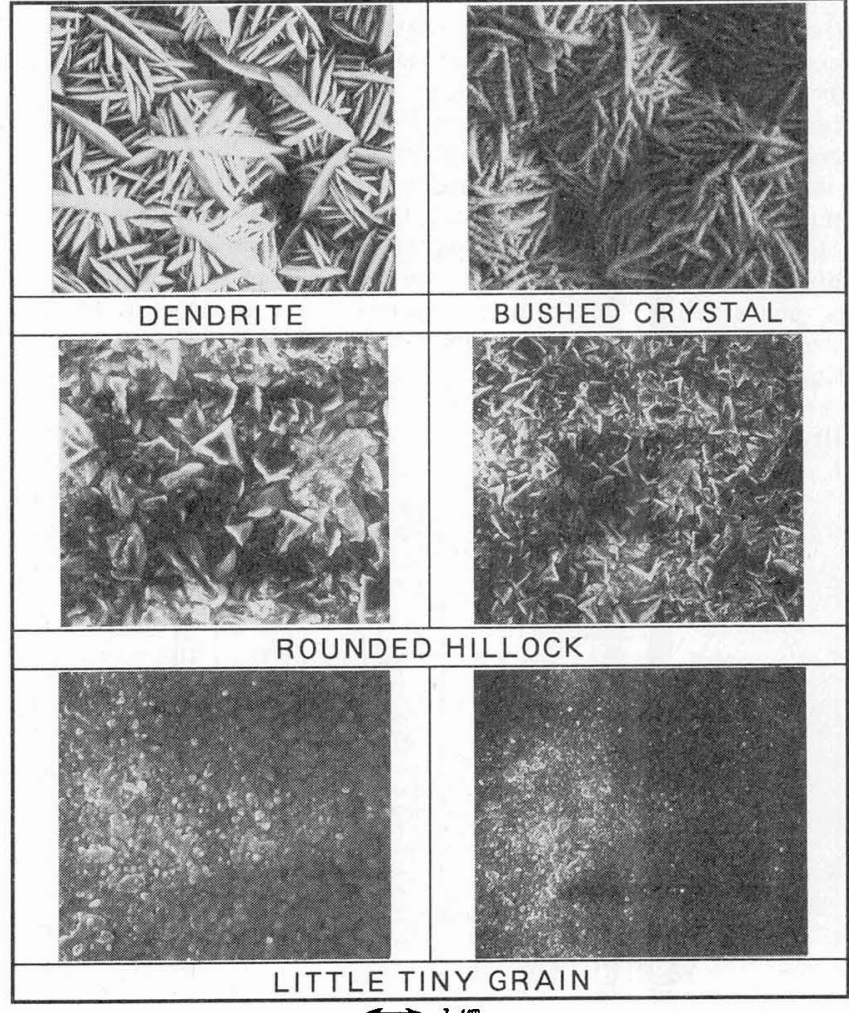

$\longleftrightarrow 1$ tm

Photo 1 Various surface appearances of tungsten carbide leyer

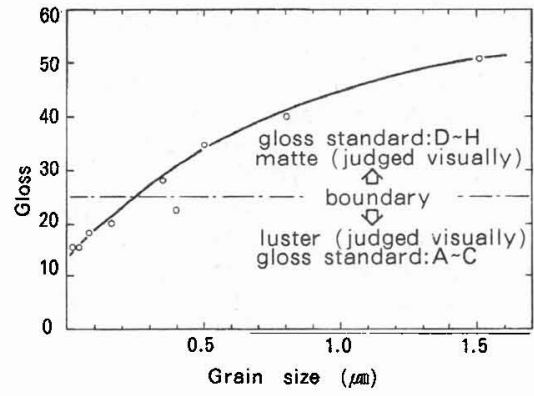

Fig.2 Relation between the grain size and the gloss

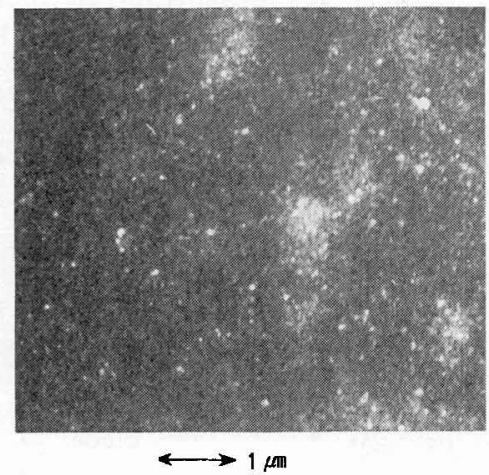

Plioto $C$ Surtace appearance of the tingsten carbide layer of the echieved quality 
process of achieving uniformity. The surface picture of the tungsten carbide layer of the achieved quality is given in Photo 2 , a sectional picture in Photo 3 , and the X-ray diffraction pattern in Figure 3.

What was most important in creating uniformity, was matching the feed rate of the reaction gas to the an reaction rate on the substrate surface $(6,7)$.

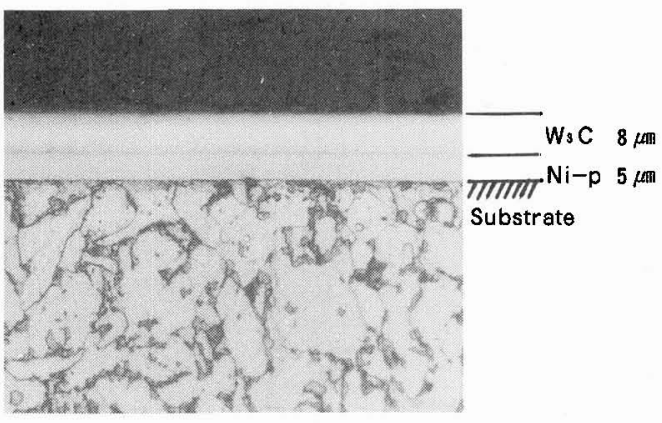

Photo 3 Cross section of the tungsten carbide layer of the achieved quality

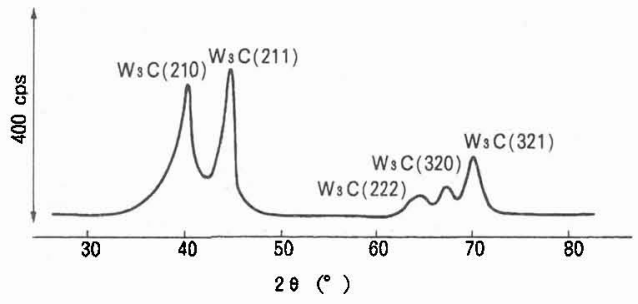

Fig.3 $X$-ray diffraction pattern of tungsten carbide

\section{Characteristic Evaluation Test Results of Tungsten Carbide Layer}

3-1 Hardness At Elevated Temperature

The hardness at elevated temperature in vacuum is compared with other materials in

Figure 4.

\section{3-2 Oxidation Resistance}

Figure 5 shows the comparison of the oxidation rate when heated in air with TiC coating.

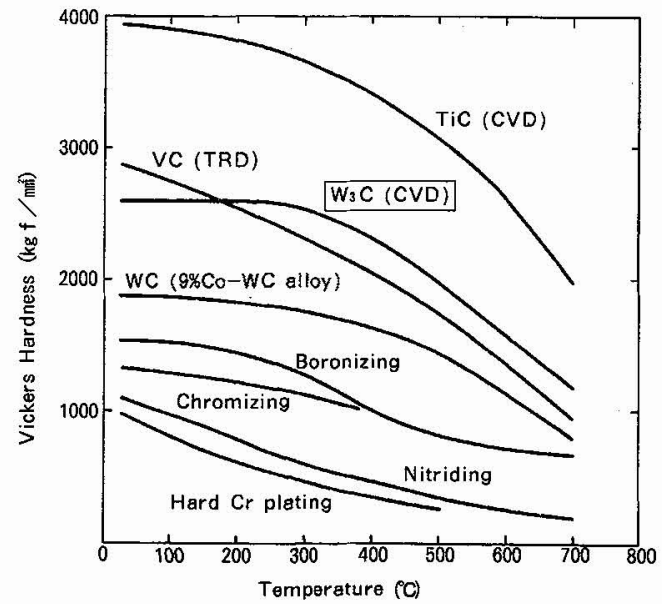

Fig.4 Comparison of hardness at elevated temperature with other hard materials.

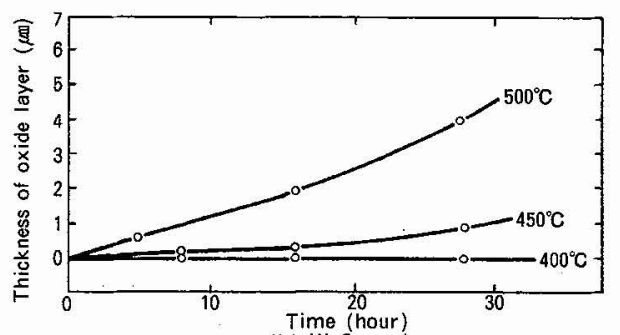

(b) Ws costing

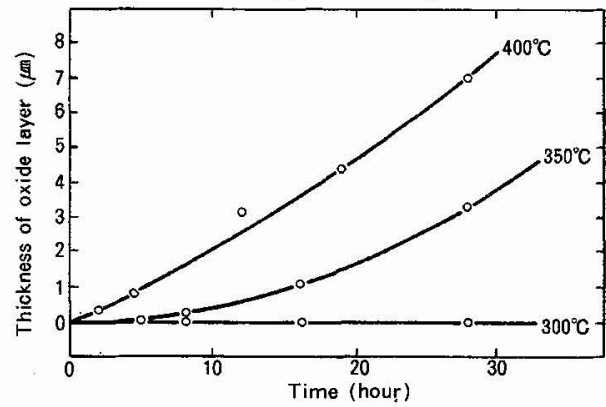

(a) TiC coating

Fig.5 Progress rate of oxidation of $\mathrm{TiC}$ and $\mathrm{W}_{3} \mathrm{C}$ layer 


\section{3-3 Wear Resistance}

Figure 6 shows a comparison of the coefficient of friction and wear rate with other materials using the pin and disk friction and wear test.

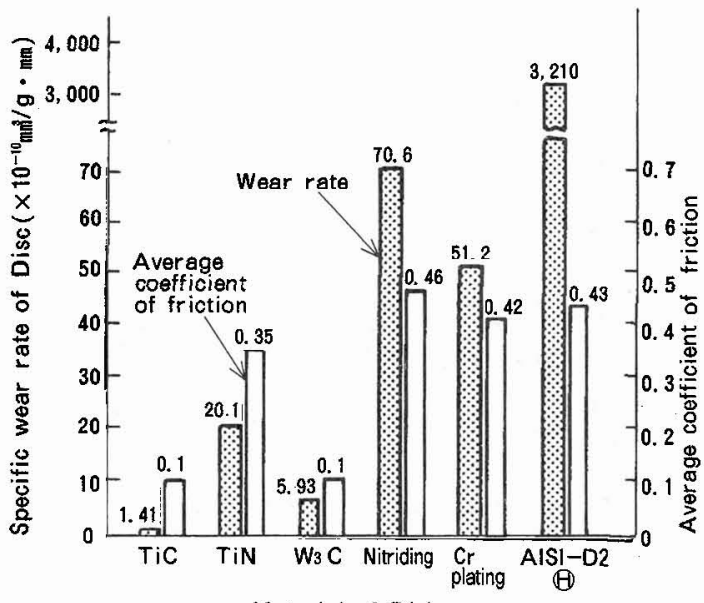

Material of Disk

(a) Wear rate of Disk
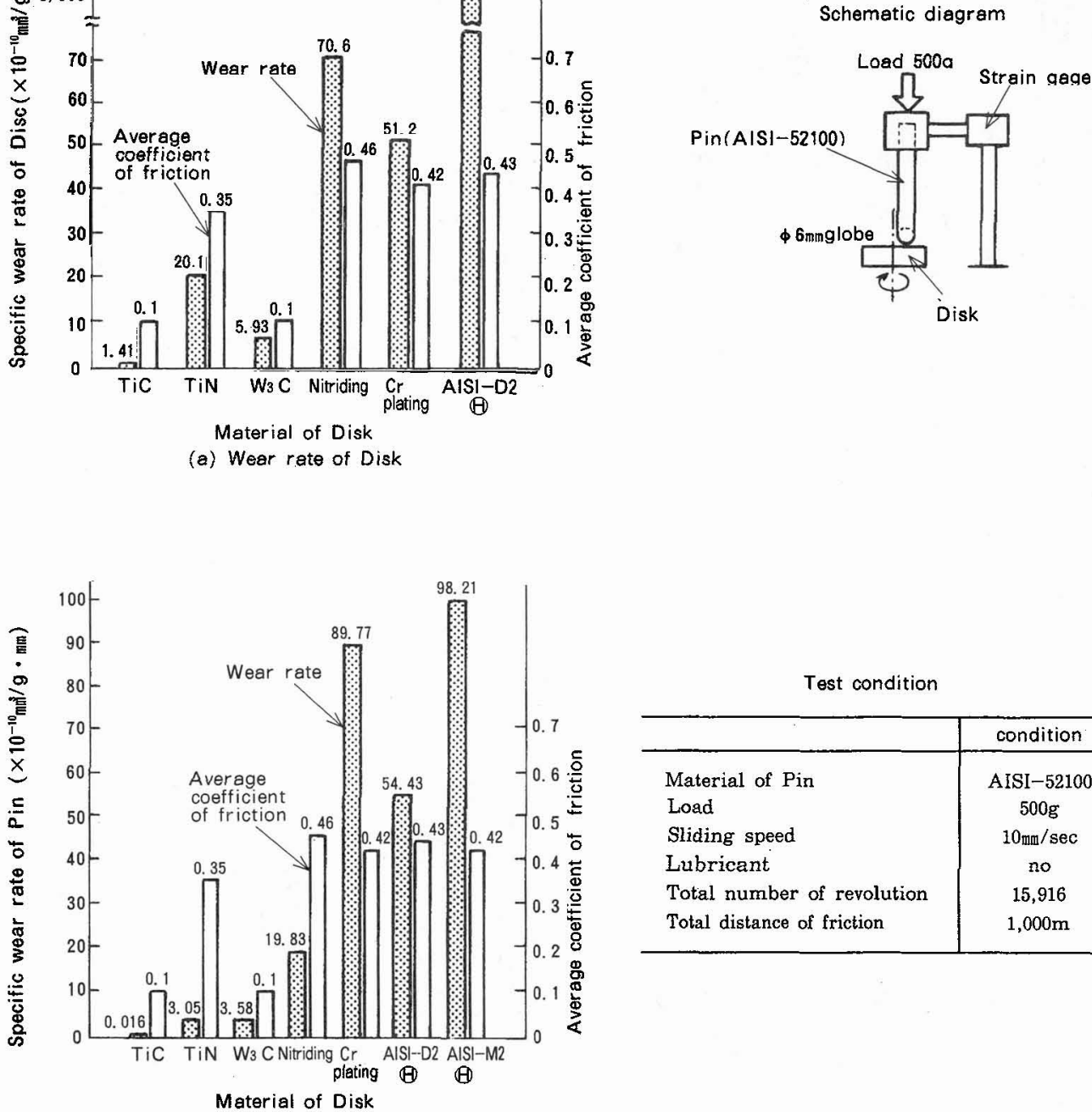

Test condition

\begin{tabular}{l|c}
\hline & condition \\
\hline Material of Pin & AISI-52100 \\
Load & $500 \mathrm{~g}$ \\
Sliding speed & $10 \mathrm{~mm} / \mathrm{sec}$ \\
Lubricant & no \\
Total number of revolution & 15,916 \\
Total distance of friction & $1,000 \mathrm{~m}$
\end{tabular}

(b) Wear rate of Pin

Fig6. Comparison of wear resistance by Pin-Disk tester with other materials 


\section{3-4 Corrosion Resistance}

Figure 7 and 8 show the comparative results of weight loss due to corrosion with other materials, when immersed in $15 \% \mathrm{HCl}$ aqueous solution, and $15 \% \mathrm{H}_{2} \mathrm{SO}_{4}$ aqueous solution, respectively.

\section{(Subsrate)}

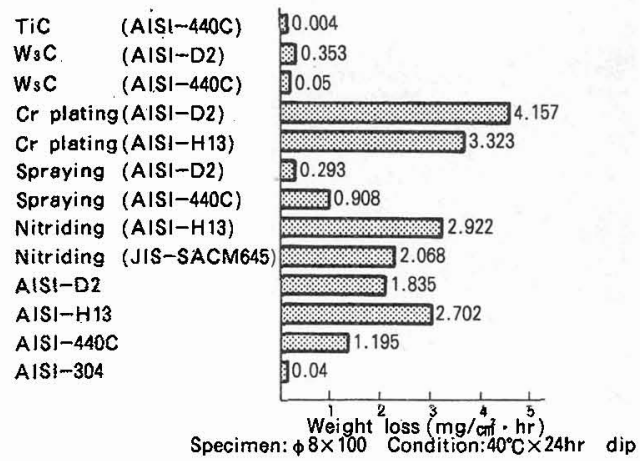

Fig. 7 Comparison of corrosion resistance in $15 \% \mathrm{HC}$ solution with other materials

\section{(Subsrate)}

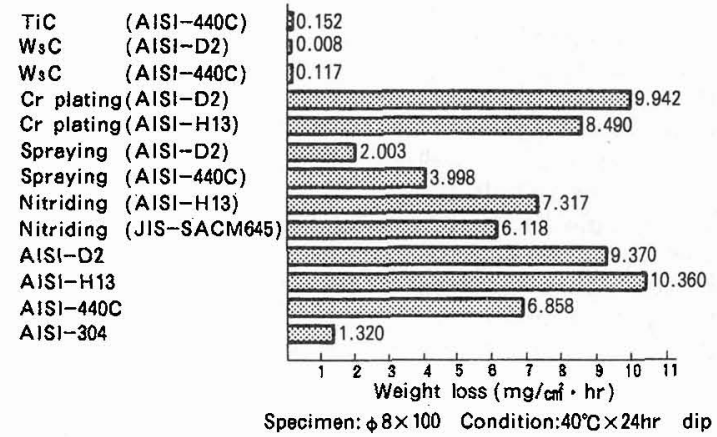

Fig. 8 Comparison of corrosion resistance in $15 \% \mathrm{H}_{2} \mathrm{SO}_{4}$ solution with other materials

\section{3-5 Parting Property}

Pellets of polycarbonate put on a substrate were heated at $330^{\circ} \mathrm{C}$ in $\mathrm{N}_{2}$ atmosphere, melted, and cooled at room temperature. The load required to separate them from the coated substrate was measured by a simple method. Photo 4 shows the polycarbonate melted and cooled on the coated substrate. Figure 9 gives a Schematic diagram of the measuring apparatus, and Figure 10 shows the results when compared with other materials.

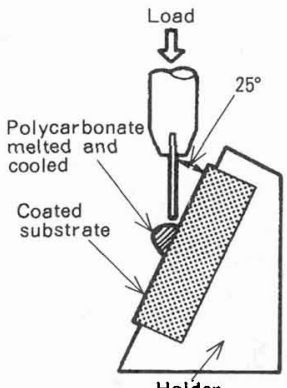

Holder

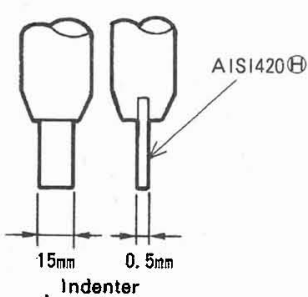

Indenter

Fig.9 Schematic diagram of parting test apparatus

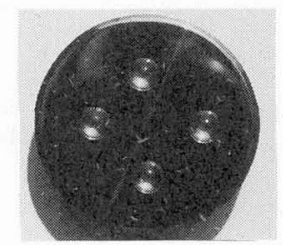

Photo 4 Polycarbonate melted and cooled on coated substrate

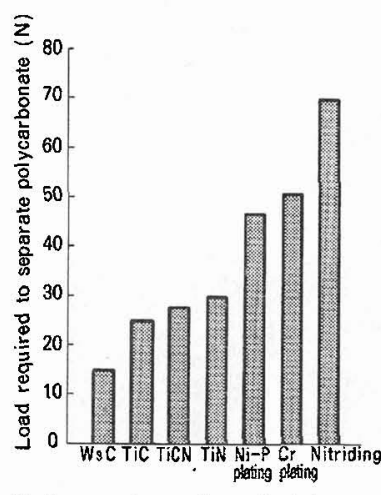

Fig. 10 Comperison of parting property with other materials 


\section{Results of Practical Use}

Recently there has been an increasing demand for engineering plastics, and super-engineering plastics. Therefore wear resistance, corrosion resistance and parting properties are required in the mechanical parts molding them by injection or ejection.

Making use of these characteristics of tungsten carbide coating, as well its low distortion and high throwing power, we can achieve successful results when applied to these parts. Some of the examples are given below.

4-1 Cylinder (Photo 5)

In the case of cylinders fabricated in an injection molding machine, using a mixture of $40 \%$ glass fiber in PPS at $300-330^{\circ} \mathrm{C}$, the nitrided cylinder had to be replaced after about 8 months, and the alloy-lined cylinder after about 12 months due to wear. However, the cylinder having the inner surface coated with tungsten carbide could be used for about 2.5 years.

\section{4-2 Screw (P hoto 6)}

In the case of screws fabricated in injection molding machine, using fluoroplastiancs (PFA) at $350-360^{\circ} \mathrm{C}$, the hard chrome plated screw must be polished to remove surface deposits which cause contamination and degeneration once every three or four days. Pitting was also caused by HF in the course of use and contamination was further increased. By contrast, the tungsten carbide coated screw was free from contamination or pitting corrosion after several months of use.

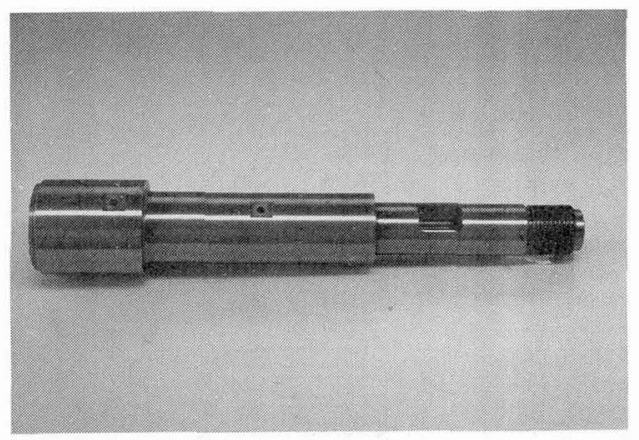

Photo 5 Cylinder

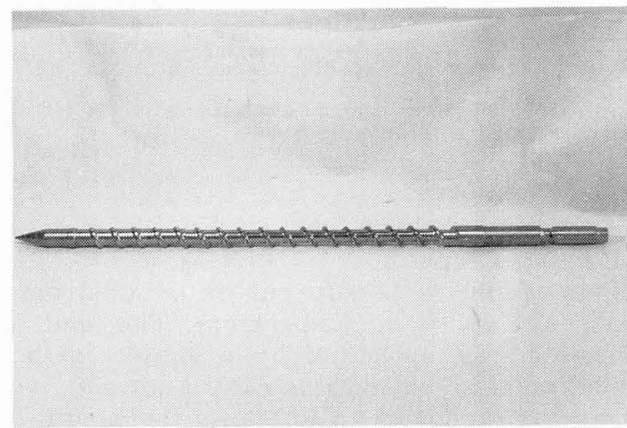

Photo 6 Screw

4-3 Cylinder Head, Intermediate Nozzle, Nozzle (Photo 7)

Screw Head, Counterflow Preventive Ring, Seal Ring (Photo 8)

In these parts, too, excellent results were achieved, such as, wear resistance to resin mixed with glass fiber, corrosion resistance and contamination resistance to resin generating corrosive gases and contamination resistance to polycarbonate or transparent resins.

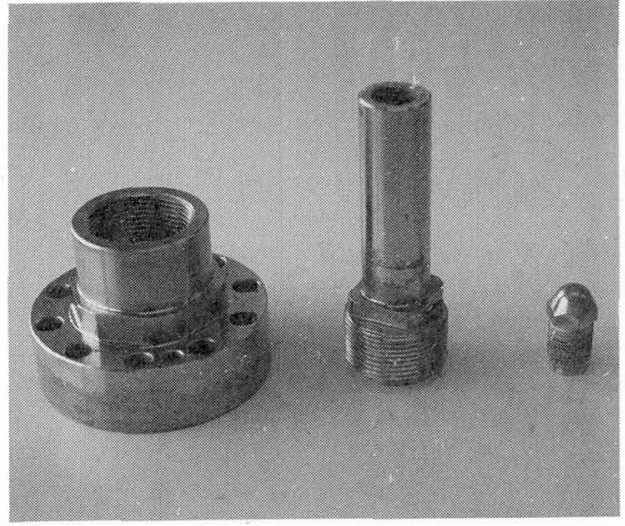

Photo 7 Cylinder head, intermediate nozzle, nozzle

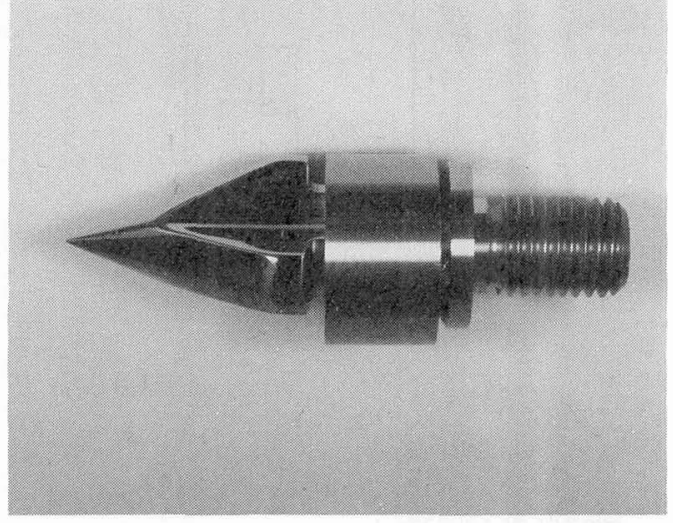

Photo 8 Screw head, counterflow preventive ring, seal ring 
4-4 Grained Die (Photo 9)

In the case of a grained die, for an injection molding machine using phenol resin at $75-150^{\circ} \mathrm{C}$, an untreated steel die is normally used. Using this material, however, parting of the molded products was poor, and many defective pieces were produced. In addition, after repeated use, the graining pattern disappeared due to wear.

In the case of the grained die coated with tungsten carbide, the parting performance is smooth, defective formed pieces are

eliminated, and wear of the graining surface is hardly noticed.

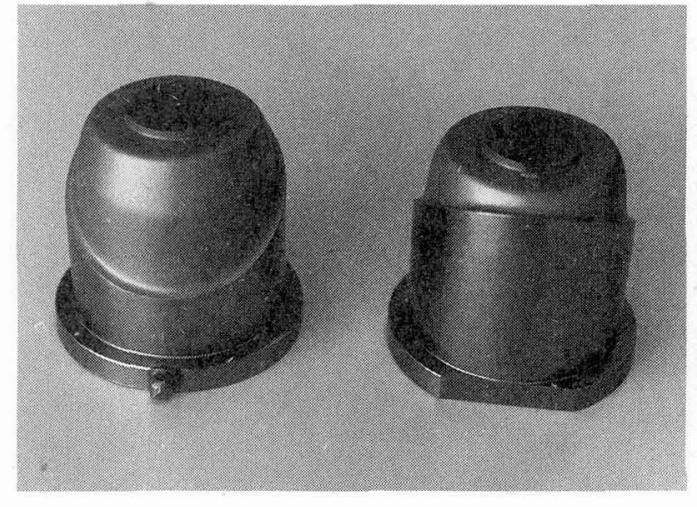

Photo 9 Grained die

\section{Reference}

1. N.J. Archer: Proc. Chem. Vapor Deposition, 5 (1975) 556

2. N.J. Archer, K.K. YEE: Wear, 48 (1978) 237

3. N.J. Archer: The Chemical Engineer, 12 (1974) 780

4. British Patent 1,326,769 (1973)

5. British Patent Application 11,818 (1975)

6. K. Sugiyama: Zairyokagaku, 2 (1978) 9

7. S. Motojima: Kinozairyo, 2 (1986) 33 